\title{
BMI, Weight Stability and Mortality among Adults without Clinical Co-Morbidities: A 22-Year Mortality Follow-Up in the Finnish Twin Cohort
}

\author{
Maarit Korkeila $^{a} \quad$ Aila Rissanen $^{b} \quad$ Thorkild I.A. Sørensen $^{c} \quad$ Jaakko Kaprio $^{a, d, e}$ \\ ${ }^{a}$ Department of Public Health, University of Helsinki, \\ ${ }^{b}$ Obesity Research Unit, Helsinki University Central Hospital, Helsinki, Finland \\ ${ }^{c}$ Institute of Preventive Medicine, Copenhagen University Hospital, Centre for Health and Society, Copenhagen, Denmark \\ ${ }^{\mathrm{d}}$ Department of Mental Health, National Institute for Health and Welfare, \\ ${ }^{\mathrm{e}}$ Institute for Molecular Medicine, University of Helsinki, Helsinki, Finland
}

\section{Key Words}

Body weight - Cause of death - Mortality .

Weight changes · Discordant twins

\section{Summary}

Aim and Method: Cause-specific mortality was studied in relation to body mass index (BMI) and weight stability (defined as less than $1 \mathrm{BMl}$ unit change during a 6-year period) in 15,424 initially healthy twin subjects from the Finnish Twin Cohort, first examined in 1975, re-examined in 1981, and then followed over 22 years (1982-2003). Additionally, death discordant twin pairs were studied to assess whether body weight differences are associated with mortality independent of childhood factors and genetic background. Deaths and cause of death were ascertained from national registries. Associations with mortality were estimated by Cox proportional hazards model for all individuals and conditional logistic regression analysis for pairwise analyses. Results: Mortality increased with increasing BMI for all causes and coronary heart disease (CHD) in men, and there were no associations for all natural causes, cerebrovascular disease, and violent deaths. After adjustment for multiple co-variates and changes in co-variates between 1975 and 1981, BMI was associated with CHD mortality in all men (hazard ratio $(H R)=1.22$, 95\% $\mathrm{Cl} 1.06-1.41)$ and in men with stable weight between 1975 and 1981 ( $\mathrm{HR}=1.26,95 \% \mathrm{Cl} 1.03-1.55)$. Overall risk of death and cause-specific mortality was not associated with BMI in women. Conclusion: Among clinically healthy subjects at low risk of death, BMI appears to be associated with $\mathrm{CHD}$ risk in men.

\section{Introduction}

Several epidemiological studies have demonstrated either linear or J- or U-shaped relationship between mortality and body weight [1-7] Recent large population-based studies have suggested that mortality is lower among normal-weight subjects than among underweight, overweight or obese subjects $[8,9]$. However, it has been debated where on the scale between overweight and obesity the risk for mortality actually increases as some recent studies have shown that mortality is lower among overweight than normal-weight subjects [10].

Most studies on weight and mortality are based on body mass index (BMI), which is dependent on the size of the lean and the fat body mass [11]. The risks for co-morbidities like cardiovascular diseases and type 2 diabetes tend to increase linearly with increasing BMI [12-16].

Studies of weight change and mortality are beset with methodological problems like confounding by smoking, intentional weight loss and pre-existing morbidities, which make interpretations and comparisons of results from various studies difficult. On one hand, modest weight loss leads to metabolic benefits[17-23], but on the other hand weight loss has been associated with excess mortality in cohort studies $[14,15,24]$. Cohort studies [25] as well as prospective longitudinal studies have concluded that stable weight may promote health over time [16, 26, 27]. In our recent study from the Finnish Twin Cohort on healthy overweight and obese subjects, intentional weight loss over 6 years predicted an almost two-fold increase in mortality compared to stable weight in initially healthy overweight and obese subjects [28], with weight gain also predicting increased risk of death. Since any single measurement

\section{KARGER}

Fax +497614520714

Information@Karger.de

www.karger.com (c) 2009 S. Karger GmbH, Freiburg

Accessible online at:

www.karger.com/ofa
Prof. Dr. Jaakko Kaprio

Department of Public Health

University of Helsinki

P.O.Box 41, 00014 Helsinki, Finland

Tel. +358 9 191-1, Fax -27600

jakko.kaprio@helsinki.fi 
Fig. 1. The Finnish Twin Cohort. Flowchart showing the delineation of the study sample by various exclusions at baseline in 1975 .

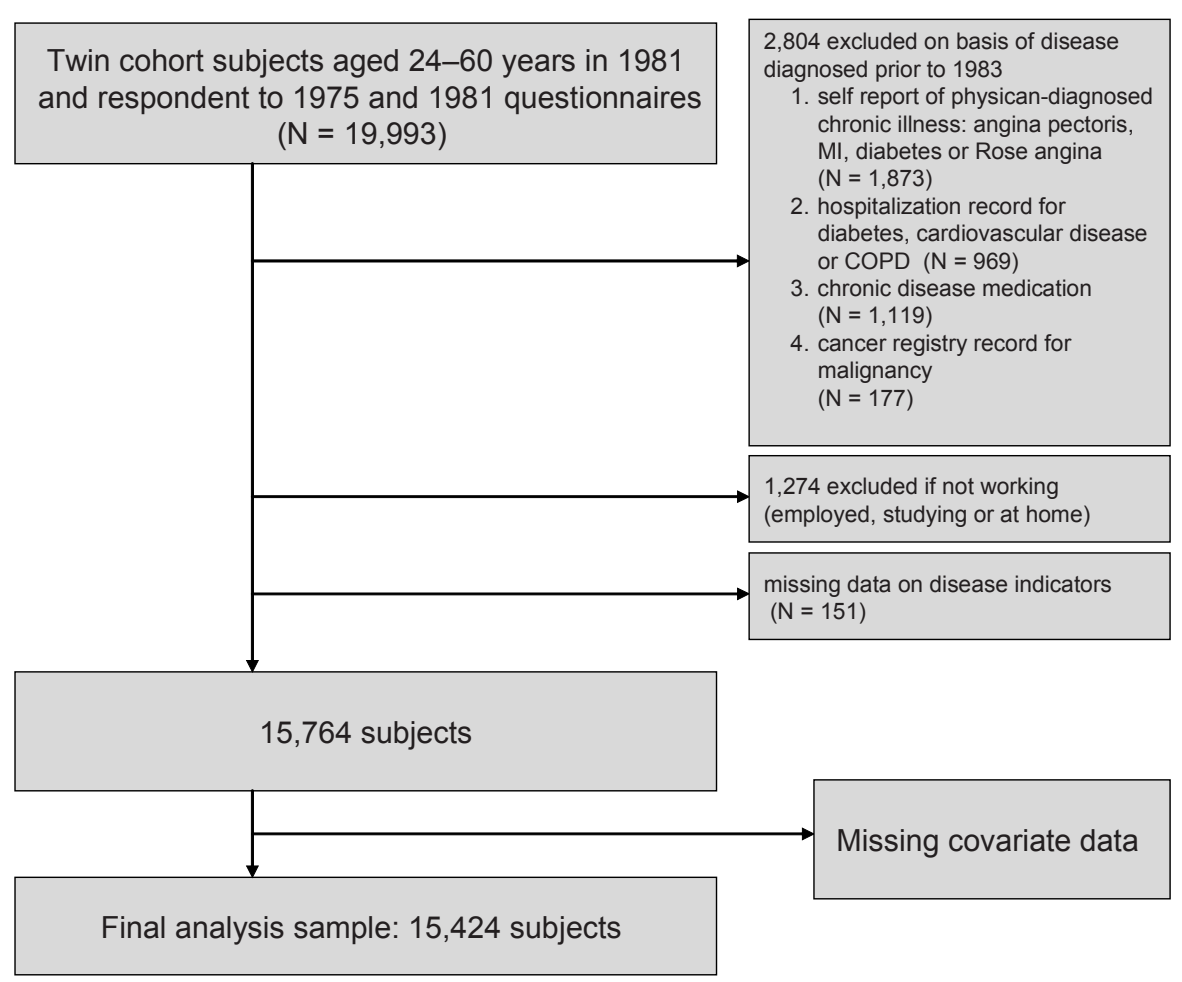

ed prior to 1983 . angina pectoris, Missing covariate data or report of concurrent body weight will provide a mixture of subjects with stable body weight and changed body weight, it is possible that the BMI-mortality association when based on a single point correspondingly reflects mixed effects of stable and changed BMI on mortality.

It is also possible that the hitherto observed associations between weight change and mortality are confounded by genetic or early environmental influences. Applying the co-twin control method, based on comparison of twin pairs discordant for the phenotype under study, it may be possible to disentangle effects of the individual environment, causing weight differences, and effects attributable to genes and early shared environment [29]. A limited number of studies with co-twin control design have been published, a few of them focused on mortality [30-32] and a few others on obesity [33-36]. The co-twin control design may be used to assess if individual environmentally induced differences in body weight and weight changes are associated with subsequent mortality.

Our previous study focused on the intentional weight loss and mortality in overweight and obese subjects over 6 years. The aim of the present study was to further examine how the whole range of BMI assessed at two time points 6 years apart, and stable body weight over time, are related to all-cause and cause-specific mortality during a 22-year follow-up among adult subjects, in whom all indications of co-morbidities and high-risk conditions and behaviors have been effectively excluded or are controlled for. Finally we investigated whether observed associations between BMI and mortality in individuals were preserved when controlling for genetic and shared environmental influences.

\section{Material and Methods}

This study is based on the Finnish Twin Cohort, including all same-sex twin pairs born in Finland before 1958, and with both twin members alive in 1967 [37]. The participants received questionnaires in 1975 and in 1981 addressing height, weight, lifestyle issues, sociodemographic factors and physician-diagnosed diseases. The response rate in the 1975 survey was $89 \%$. Among those still alive at the 1981 survey and who had responded in 1975 , the response rate was $91 \%$. The present study sample was derived from the 19,993 participants aged 24-60 years in 1981. The further delineation of the study sample is illustrated in figure 1 . The final number of subjects included in the present study was 15,494 subjects with 22-year mortality follow-up (1972-2003).

As described in detail earlier [28,32], we excluded from the analysis sample participants suffering from any recognized chronic disease (based on questionnaire information and national medical registries) that could induce weight loss during 1975-1982 and subsequently increase mortality. We excluded also participants who had received fully-reimbursed prescriptions for major chronic diseases except for hypertension; the common condition was included as a co-variate. A total of 2,804 persons were excluded on the basis of known diseases. Finally, in order to take into account possible ill health not recorded otherwise, we excluded 1,274 participants who were not working in 1981 (i.e. being on early or disability pension, unemployed or otherwise not employed) as described in detail elsewhere [28]. Further exclusions due to missing data in co-variates are described below.

BMI was calculated from the reported height in the 1975 survey and from weight in both surveys. Self-reported current height and weight generally have high accuracy $[38,39]$ and the accuracy of the reports used in the present study is supported by an analysis of another sub-study of the Finnish Twin Cohort [40].

The subjects were categorized as underweight (BMI under $18.5 \mathrm{~kg} / \mathrm{m}^{2}$ ), normal weight $\left(18.5\right.$ to $\left.<25 \mathrm{~kg} / \mathrm{m}^{2}\right)$, overweight $\left(25\right.$ to $\left.<30 \mathrm{~kg} / \mathrm{m}^{2}\right)$ or obese $\left(\geq 30 \mathrm{~kg} / \mathrm{m}^{2}\right)$ according to a BMI-based classification of the International Obesity Task Force (IOTF) [13]. Three classes of normal-weight subjects were used $\left(18.5\right.$ to $<22 \mathrm{~kg} / \mathrm{m}^{2}, 22$ to $<23.5 \mathrm{~kg} / \mathrm{m}^{2}, 23$ to $<25 \mathrm{~kg} / \mathrm{m}^{2}$ ) Nor- 
Table 1. Number of subjects at baseline and number of deaths to the end of 2003 among clinically healthy subjects from the Finnish Twin Cohort in classes of BMI in 1975.

\begin{tabular}{|c|c|c|c|c|}
\hline \multirow[t]{2}{*}{ BMI class } & \multicolumn{2}{|l|}{ Women } & \multicolumn{2}{|l|}{ Men } \\
\hline & number of subjects & number of deaths & number of subjects & number of deaths \\
\hline \multicolumn{5}{|l|}{ Underweight } \\
\hline$<18.5 \mathrm{~kg} / \mathrm{m}^{2}$ & 700 & 20 & 129 & 2 \\
\hline \multicolumn{5}{|l|}{ Normal weight } \\
\hline 18.5 to $<22 \mathrm{~kg} / \mathrm{m}^{2}$ & 3,926 & 140 & 2,330 & 149 \\
\hline 22 to $<23.5 \mathrm{~kg} / \mathrm{m}^{2}$ & 1,209 & 58 & 1,688 & 144 \\
\hline 23.5 to $<25 \mathrm{~kg} / \mathrm{m}^{2}$ & 859 & 63 & 1,513 & 182 \\
\hline \multicolumn{5}{|l|}{ Overweight } \\
\hline 25 to $<27 \mathrm{~kg} / \mathrm{m}^{2}$ & 569 & 47 & 1,160 & 158 \\
\hline 27 to $<30 \mathrm{~kg} / \mathrm{m}^{2}$ & 368 & 34 & 669 & 119 \\
\hline \multicolumn{5}{|l|}{ Obese } \\
\hline$\geq 30 \mathrm{~kg} / \mathrm{m}^{2}$ & 136 & 14 & 168 & 33 \\
\hline Total & 7,767 & 376 & 7,657 & 787 \\
\hline
\end{tabular}

mal-weight subjects with BMI 18.5 to $<22 \mathrm{~kg} / \mathrm{m}^{2}$ were used as a reference group in mortality analyses. Overweight subjects were split as over and under BMI of $27 \mathrm{~kg} / \mathrm{m}^{2}$ while the number of obese subjects did not permit subgroup analyses. Given gender differences in both body composition and mortality, all analyses were done separately for men and women.

Mortality analyses were also conducted using BMI z-scores, i.e. units of 1 standard deviation (SD) for BMI in 1975 or 1981, computed separately by sex in order to investigate if there is a change in the association between these two time points. Weight-stable subjects were defined as those whose BMI changed by less than 1 BMI unit between 1975 and 1981, while weight-unstable subjects were those who had changed by either loss or gain by 1 BMI unit or more.

The lifestyle factors (smoking, binge drinking, leisure physical activity, life dissatisfaction) were asked at both surveys and recorded in simpler categories in order to avoid overloading the multivariate models. Each of these risk factors were then categorized as being present both in 1975 and 1981, only in 1975, only in 1981, or absent in both surveys, which was coded by three dummy variables [32]. Schooling (eight categories of years of schooling), social class (six categories) and income (coded as eight levels) in 1975 were also included as potential confounders. A history of hypertension was based on both questionnaire information (self-report of physician-diagnosed hypertension, regular use of antihypertensive medications), and register information on the right to full reimbursement of antihypertensive medication was used as a dichotomous measure. Physical activity at leisure and hypertension were included in the model but were regarded as mediators influenced by obesity, rather than confounders. Some of the co-variate information was missing, which led to the final sample size of 15,494 participants (fig. 1).

The participants were followed up until death, migration or the end of 2003 , and a total of 1,163 subjects ( 787 men and 376 women) died. Underlying causes of death were available from Statistics Finland [41] for all but 15 subjects. The ascertainment of causes of death was based on forensic autopsy in $40 \%$ of cases. Natural and violent causes were analyzed separately. Among natural causes, coronary heart disease (CHD; ICD 8 and 9 410-414, ICD-10 I 20-I29) and cerebrovascular disease (CVD; ICD 8 and $9430-438$, ICD-10 I60-I69) were analyzed separately and as a joint outcome. The group of violent deaths included any accidental deaths and suicides. The standardized mortality ratio of the subjects without clinically overt disease was $40 \%$ of the mortality of all the twins, who had replied to both questionnaires [28].

Discordant Pair Analyses

The considerable genetic contribution to BMI has been shown in several twin, family and adoption studies [42]. Twin analyses of the genetic and environmental effects on BMI, change in body weight, intention to lose weight, and mortality have previously been published from the Finnish Twin Cohort [28, 32, 43, 44]. One approach to control for the genetic and shared environment contribution to a modifiable risk factor, like overweight and obesity, is to study twin pairs discordant for a chosen outcome, i.e. in this study all-cause and CHD death [31,32].

The criterion for discordance was that one member of twin pair had died during the follow-up. We tested if pairs where both members had died were different with respect to BMI from pairs where only one cotwin had died and found no significant difference. We therefore present the results of comparisons of BMI among 544 twin pairs discordant for death of all causes (of which 342 were men and 158 monozygotic twin pairs (MZ)) and among 91 twin pairs (of which 67 were men and $28 \mathrm{MZ}$ ) discordant for CHD death.

\section{Statistical Analyses}

Total mortality from 1982 through 2003 was analyzed by the Cox proportional hazards regression model with time (the number of days scaled as years) since response to the 1982 survey using Stata software $[28,40]$. The estimated regression coefficients and standard errors were converted to hazard ratios (HR) with $95 \%$ confidence intervals $(95 \% \mathrm{CI})$. The analyses were done using an adjusted model including the statistically significant co-variates. Age in 1981 was used as a built-in stratification variable (age intervals 24-29 years, 30-34 years, 35-44 years, $>45$ years) allowing age to be modelled as a continuous variable within the age intervals mentioned.

The proportionality of hazards were checked by examining 'log-log' plot, i.e. $-\ln \{-\ln ($ survival $)\}$ curves for categories of the variables versus $\ln$ (analysis time) and using Schoenfeld residuals. As the twin cohort was ascertained as twin pairs, observations (i.e. twin individuals) in twin pairs may be correlated. Therefore we adjusted for this in the estimation of standard errors of the HR and the $\mathrm{p}$ values by using a robust variance estimate that adjusts for within-pair correlation [45]. Two-tailed $p$ values below 0.05 were considered statistically significant.

\section{Results}

Out of 15,494 study subjects, 1,163 (of which 787 were men) died during the 22-year follow-up (table 1). Overweight subjects made up $18 \%$ of the sample in 1975 while only $2 \%$ were obese. In 1981, $24 \%$ were overweight and $3 \%$ obese, men being more often overweight and obese than women at both time 
Table 2. Relative risk (HR and 95\% CI) of death by end of 2003 by weight category and BMI class in 1975 or 1981 for men and women. Models adjusted for age both for 1975 and 1981 BMI

\begin{tabular}{|c|c|c|c|c|}
\hline \multirow[t]{3}{*}{ BMI class } & \multicolumn{4}{|c|}{ BMI, age-adjusted, HR (95\% CI) } \\
\hline & \multicolumn{2}{|l|}{1975} & \multicolumn{2}{|l|}{1981} \\
\hline & women & men & women & men \\
\hline \multicolumn{5}{|l|}{ Underweight } \\
\hline$<18.5 \mathrm{~kg} / \mathrm{m}^{2}$ & $1.22(0.76-1.97)$ & $0.28(0.07-1.10)$ & $1.43(0.82-2.51)$ & $1.00(0.34-2.98)$ \\
\hline \multicolumn{5}{|l|}{ Normal weight } \\
\hline 18.5 to $<22 \mathrm{~kg} / \mathrm{m}^{2}$ & 1.00 (reference) & 1.00 & 1.00 & 1.00 \\
\hline 22 to $<23.5 \mathrm{~kg} / \mathrm{m}^{2}$ & $0.82(0.60-1.13)$ & $0.97(0.77-1.23)$ & $0.95(0.70-1.30)$ & $1.17(0.90-1.53)$ \\
\hline 23.5 to $<25 \mathrm{~kg} / \mathrm{m}^{2}$ & $1.04(0.77-1.40)$ & $1.15(0.90-1.45)$ & $0.93(0.67-1.30)$ & $1.02(0.78-1.33)$ \\
\hline \multicolumn{5}{|l|}{ Overweight } \\
\hline 25 to $<27 \mathrm{~kg} / \mathrm{m}^{2}$ & $0.91(0.64-1.30)$ & $1.14(0.89-1.46)$ & $1.16(0.84-1.60)$ & $1.15(0.89-1.49)$ \\
\hline 27 to $<30 \mathrm{~kg} / \mathrm{m}^{2}$ & $0.88(0.59-1.32)$ & $1.40(1.07-1.82)$ & $0.88(0.59-1.30)$ & $1.42(1.08-1.87)$ \\
\hline \multicolumn{5}{|l|}{ Obese } \\
\hline$\geq 30 \mathrm{~kg} / \mathrm{m}^{2}$ & $1.07(0.61-1.88)$ & $1.61(1.08-2.41)$ & $1.06(0.65-1.73)$ & $1.42(0.96-2.09)$ \\
\hline Per SD of BMI & $0.96(0.87-1.07)$ & $1.15(1.07-1.24)$ & $0.99(0.88-1.11)$ & $1.11(1.03-1.20)$ \\
\hline
\end{tabular}

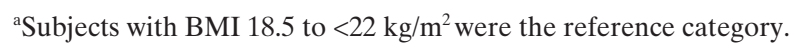

Table 3. Relative risk (HR) of mortality by cause of death by end of 2003 per SD of BMI in 1981 for men and women. Models adjusted for age and all covariates for all subjects and for weight-stable subjects

\begin{tabular}{|c|c|c|c|c|c|c|}
\hline & \multicolumn{6}{|c|}{ SD of BMI, fully adjusted, hazard ratio ( $95 \% \mathrm{CI})$} \\
\hline & \multicolumn{3}{|l|}{ all subjects } & \multicolumn{3}{|c|}{ weight-stable subjects } \\
\hline & $\begin{array}{l}\text { number of } \\
\text { deaths }(\mathrm{m} / \mathrm{f})\end{array}$ & women & men & $\begin{array}{l}\text { number of } \\
\text { deaths }(\mathrm{m} / \mathrm{f})\end{array}$ & women & men \\
\hline All causes & $787 / 376$ & $0.95(0.85-1.07)$ & $1.07(0.99-1.15)$ & $431 / 177$ & $0.89(0.74-1.07)$ & $1.08(0.96-1.21)$ \\
\hline Natural causes & $599 / 324$ & $0.96(0.85-1.08)$ & $1.07(0.98-1.17)$ & $349 / 157$ & $0.91(0.75-1.11)$ & $1.09(0.96-1.23)$ \\
\hline $\mathrm{CHD}$ & $178 / 42$ & $0.99(0.73-1.35)$ & $1.22(1.06-1.41)$ & $104 / 19$ & $0.72(0.35-1.41)$ & $1.26(1.03-1.55)$ \\
\hline CVD & $33 / 28$ & $1.19(0.91-1.55)$ & $1.00(0.68-1.47)$ & $18 / 12$ & $0.53(0.30-0.94)$ & $0.78(0.47-1.31)$ \\
\hline CHD or CVD & $205 / 73$ & $1.06(0.85-1.32)$ & $1.18(1.03-1.36)$ & $122 / 31$ & $0.71(0.44-1.12)$ & $1.18(0.97-1.44)$ \\
\hline Violent causes & $179 / 46$ & $0.87(0.60-1.25)$ & $1.09(0.94-1.27)$ & $78 / 17$ & $0.74(0.39-1.40)$ & $1.01(0.76-1.33)$ \\
\hline
\end{tabular}

Note: Models adjusted for age and all covariates (leisure time physical activity, smoking, hypertension, binge drinking, life satisfaction, income, schooling and social class).

points. The mean BMI ( \pm SD) in 1981 was $24.3 \pm 2.85 \mathrm{~kg} / \mathrm{m}^{2}$ in men and $22.6 \pm 3.3 \mathrm{~kg} / \mathrm{m}^{2}$ in women. The mean change in BMI between 1975 and 1981 was $0.76 \pm 1.61 \mathrm{~kg} / \mathrm{m}^{2}$. The mean age of women and men was 36.0 and 36.1 years in 1981, respectively.

\section{Single BMI Measurement and Subsequent Mortality}

The total mortality increased approximately linearly with baseline BMI for men, but did not show any such relation in women (table 2) when adjusted for age and taking into account the significant co-morbidities of BMI by using them as exclusion criteria. The increase in risk for men was $15 \%(95 \%$ CI 7-24\%) per BMI z-score unit in 1975 and $11 \%$ (95\% CI 3-20\%) per BMI z-score unit in 1981. Including a quadratic or higher-order terms for BMI did not improve model fit.
After including further co-variates and changes in them into the Cox regression models (age in 1981, smoking, binge drinking, physical activity at leisure, hypertension, education, social class and income) the associations among men became weaker with the increase per BMI z-score in 1981 being 7\% (95\% CI -1 to $15 \%$ ) (table 3 ). This relationship was not modified by hypertension $(\mathrm{p}$ for interaction $=0.21$ ). When hypertension was excluded from the model the increase per BMI score was $8.5 \%$ (95\% CI 1-17\%).

Among men, the increase in mortality during the 22-year follow-up appeared approximately linear across all categories of baseline BMI (fig. 2), with a significant difference from the reference category only among moderately overweight subjects (BMI 27-30 kg/m²). For women no association of BMI with mortality was seen (table 2 and fig. 2). The women 
Fig. 2. Individual based analysis. Cumulative HR (y-axis) for 22-year mortality by category of BMI in 1981 (x-axis) among 15,494 subjects from the Finnish Twin Cohort for men (continuous line) and women (dotted line) separately. The non-significantly increased risks of mortality of underweight subjects are not shown due to wide confidence intervals.

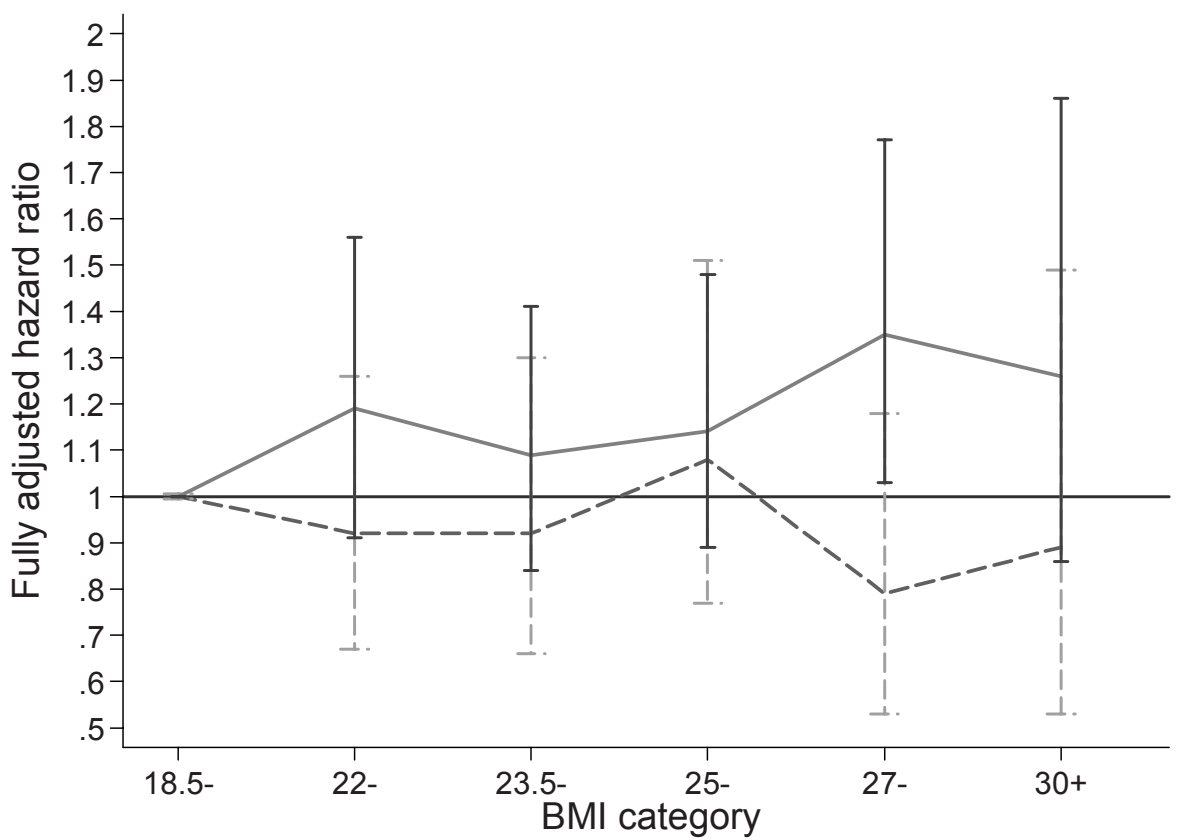

Table 4. HRs for CHD mortality by weight category and BMI class among men in 1975 and 1981.

\begin{tabular}{lll}
\hline BMI class & 1975 & 1981 \\
\hline $\begin{array}{l}\text { Underweight } \\
\quad<18.5 \mathrm{~kg} / \mathrm{m}^{2}\end{array}$ & - & - \\
Normal weight & & \\
18.5 to $<22 \mathrm{~kg} / \mathrm{m}^{2}$ & 1.00 & 1.00 \\
22 to $<23.5 \mathrm{~kg} / \mathrm{m}^{2}$ & $1.03(0.53-2.00)$ & $1.09(0.53-2.23)$ \\
23.5 to $<25 \mathrm{~kg} / \mathrm{m}^{2}$ & $1.97(1.09-3.57)$ & $1.51(0.78-2.93)$ \\
Overweight & & \\
25 to $<27 \mathrm{~kg} / \mathrm{m}^{2}$ & $1.88(1.02-3.46)$ & $1.81(0.94-3.46)$ \\
27 to $<30 \mathrm{~kg} / \mathrm{m}^{2}$ & $2.42(1.29-4.51)$ & $1.95(1.00-3.81)$ \\
Obese & & \\
$\quad 230 \mathrm{~kg} / \mathrm{m}^{2}$ & $2.00(0.82-4.86)$ & $1.83(0.77-4.31)$ \\
\hline
\end{tabular}

$-=$ Not estimated.

Note: Models adjusted for all covariates (leisure time physical activity, smoking, hypertension, binge drinking, life satisfaction, income, schooling and social class).

had a nonsignificantly increased risk of death among underweight subjects (table 2), accounted for mainly by smoking: among never smokers, the point estimate of mortality among those with BMI $<18.5 \mathrm{~kg} / \mathrm{m}^{2}$ was not increased compared with normal-weight subjects (HR 0.84, 95\% CI 0.33-2.17), while among current smoker women, the HR was 1.53 (95\% CI 0.72-3.33).

Among men the mortality risk increased with increasing BMI in 1981 only in those with CHD (HR 1.22 per BMI SD, 95\% CI $=1.06-1.41)$ (table 3 ). The risks approximately doubled from the leanest normal weight (BMI 18.5 to $<22 \mathrm{~kg} / \mathrm{m}^{2}$ ) to those with $\mathrm{BMI} \geq 27 \mathrm{~kg} / \mathrm{m}^{2}$ in an approximately linear man- ner by category of BMI (table 4). The combined category of CHD and CVD also showed an increased risk (table 3 ). Again, this relationship between BMI and CHD risk in men was not modified by hypertension ( $\mathrm{p}$ for interaction $=0.48$ ). For other cause-of-death categories no significant associations were observed. For women, no associations were seen (table 3) with any causes of death.

\section{Stable BMI and Subsequent Mortality}

When these analyses were restricted to those with stable weight (less than 1 BMI unit change between 1975 and 1981), the risk remained elevated for CHD among men (HR 1.26, 95\% CI 1.03-1.55); and the point estimate (not significant) for combined CHD and CVD did not change for men. Overall the risk estimates were very similar for all subjects and for weight-stable subjects only. Among the women with stable weight, BMI was inversely associated with risk of CVD, but this was based on 12 deaths only (table 3 ).

\section{Analysis in Twin Pairs Discordant for All-Cause and CHD Mortality}

There were no statistically significant intra-pair differences in baseline BMI or BMI at 6-year follow up among twin pairs discordant for death of all causes, whether defined as one having died and the other still alive or when comparing the first death versus later death. For pairs discordant for death from $\mathrm{CHD}$, there was an increased risk of death associated with BMI z-score at baseline (crude OR 2.27, 95\% CI 1.29-4.01, $\mathrm{p}=0.005$; OR 2.44, 95\% CI 1.20-4.95, p =0.014, when adjusted for physical activity, smoking, drinking, life satisfaction and hypertension) and at 6-year follow-up (crude OR $1.89,95 \%$ CI 1.12-3.18, $\mathrm{p}=0.017$; adjusted OR 2.93, 95\% CI $1.33-6.49, \mathrm{p}=0.008$ ) among male pairs. No association was 
seen in female pairs (OR 1.05, $\mathrm{p}=0.89$; adjusted $\mathrm{OR}=1.36$ $\mathrm{p}=0.38$ ). Among men, a significant association was seen only in dizygotic twin pairs (DZ) (crude OR 2.52, 95\% CI 1.23-5.18, $\mathrm{p}=0.012$ for $1975 \mathrm{BMI}$; adjusted $\mathrm{OR}=2.37,95 \%$ CI 1.18 4.74, $\mathrm{p}=0.015$ ), but not MZ (crude OR 1.67, $\mathrm{p}=0.45$; adjusted OR $0.91, \mathrm{p}=0.88$ ). It should be noted that only 19 male pairs discordant for CHD were MZ compared to $42 \mathrm{DZ}$.

We also tested whether a large intra-pair difference in BMI in 1975 and in 1981 of the twins in a pair affected the mortality of an individual with the idea that the BMIs of both members of a twin better represent the true value of BMI than a single measure. In models with BMI at the 6-year follow-up, the intra-pair difference categorized into tertiles (due to the skewed distribution) did not independently predict risk of death overall or from CHD among men or women.

\section{Discussion}

The main finding of this study is that in the present large cohort of healthy adults with long mortality follow-up mortality appears to increase with increasing BMI only in men, in particular in those with CHD. Stable BMI showed the same relation to increased risk for CHD mortality among these initially healthy men. Analyses on twin pairs discordant for death showed that BMI differences between twins in a pair, who are more similar to each other than randomly selected people in the population, increases risk for CHD mortality in men.

Several studies have reported a J- or U-shaped relationship between mortality and body weight $[1,3,6]$. However, in the present study the relationship between 22-year mortality and BMI was approximately linear in men and absent in women. This may be explained by the rigorous exclusions and adjustments of the study population, resulting in few suffering from co-morbidities or being at high risk of co-morbidities throughout the range of BMI so that the population may be considered representative of a cohort of initially healthy adults. The overall mortality of our sample was considerably under expectation [41], and these results should not be interpreted as risk estimates for obese or lean subjects with comorbidities. Neither does the number of deaths in the dataset allow us to distinguish a fully linear relationship from U- or J-shaped associations with certainty. However, this study, like earlier prospective studies on women and men, suggests that stable weight may predict longevity [26, 27]. In the present study, the focus in separating stable and unstable weight was to examine stable weight, as a better measure of 'true' BMI and its relationship to mortality. The unstable weight group is heterogeneous in the causes of the actual weight change, and so was not examined in more detail, as the primary group of interest was the weight-stable part of the sample. Other and larger studies are needed to tease out the factors contributing to weight change and the degree of fluctuation in weight in relation to health outcomes.
Several earlier population-based studies have reported overweight, obesity and weight gain relate to increased mortality of all causes and cardiovascular diseases in particular [3, 16]. Thus, we were not surprised to see overweight as a risk factor for all-cause and cardiovascular mortality, particularly among men. Observing the same association between stable BMI and later mortality confirms that the associations based on BMI values assessed in single time points are not primarily driven by the subgroups who have had changing BMI before that time point. It should be noted that the present study does not address the general level of mortality among those with stable weight versus those with unstable weight.

Our results of discordant twin pairs confirm that overweight is a risk factor for cardiovascular mortality. The earlier studies, based on co-twin control design, which we have retrieved, did not focus on weight and cause-specific mortality. Swan and Carmelli [46] studied weight changes among US male veterans who quit smoking, and Eisen et al. [33] studied smoking, alcohol consumption and obesity among 1,911 male US MZ veterans. The results from these studies show that past smokers were heavier than their co-twins. The earlier studies from the Finnish Twin Cohort based on co-twin control design have shown that smoking and sedentary lifestyle were risk factors for CHD in men, and high alcohol consumption relates to increased total mortality $[32,37]$. The association between CHD mortality and weight was seen in our discordant male pairs even after adjusting for other lifestyle factors. The extent to which this relationship is influenced by shared genes could not be conclusively determined in the present study due to the relatively small numbers of MZ in the discordant pair analysis.

Observational studies may not be effective to detect the causality between mortality and BMI at large [47]. The degree of confounding by co-morbidity varies between different studies and may partly be explained by reverse causation [48]. While there is evidence for underweight and obesity being harmful for health, it is possible that modest degree of overweight without significant co-morbidities influences mortality less than expected. Recent studies have suggested that overweight may not be related to excess mortality compared to normal weight [49].

The association between obesity and cardiovascular risk factors may change over time [50]. Most importantly, the association between BMI and mortality may be significantly modified by smoking, yet the confounding effect is likely to vary significantly between different cohorts $[51,52]$. The results from the present sample may not be fully representative for the situation today as the present results describe lifestyle factors from the 1970s. During the last decades smoking has decreased in men, slightly increased in women, and overweight and obesity have increased in the Finnish population.

Like in numerous earlier studies, the present analyses are based on BMI. The well-known pitfall of BMI is that it is a crude measure which does not estimate different body com- 
position compartments [53]. BMI is to a considerable degree determined by genetic factors, whereas non-shared environmental effects are greater determinants of adult weight changes [40]. Other measures of body composition, such as measures of abdominal adiposity [5], may be more specific to be used in studies on weight and mortality [54]. The relationship between different body composition measures and mortality may also vary by age [55]. The complexity of BMI-mortality relationship was studied by Gronninger [56] in a semiparametric analysis concluding that BMI, or any other categorized weight variable, may give us no or false information. The obtained estimates between BMI and mortality might be secondary to both mediators between obesity and mortality as well as to causes of obesity that influence mortality independently of obesity, like diet, physical activity and cardiovascular fitness. [56, 57]. In a large male US cohort, the relationship between CVD mortality and metabolic syndrome risk factors was entirely explained by cardiovascular fitness [58]. It is possible that metabolic syndrome risk factors do cluster in the same individuals, but we did not analyze this type of clustering in our paper. The increase in CHD risk associated with BMI in men clinically healthy at baseline may reflect future higher incidence of diabetes and hypertension among overweight and obese men compared to normal-weight men, or it may reflect the inflammatory processes seen already in young adults with acquired obesity of recent origin [59].

In spite of known problems with BMI, we chose to use it as a weight variable because comparable weight measures are needed in epidemiological studies. This study is based self-reported weights, which are possibly biased. However, the comparison of self-reported and measured weights has been ascertained in a sub-sample of this cohort and found to be sufficiently valid [40]. The use of other body composition measures could complement our knowledge on BMI-mortality association, but no such data on fat distribution or body composition was available [60-62].

The advantage of the present study is that it is based on a large nationwide cohort with longitudinal data and long follow-up on mortality, with exclusions of chronic diseases done carefully by using different sources of information. The Finnish registries also provide reliable data on mortality and cause of death. Besides using the cohort as a population-based cohort, the data also allows the specific methodological co-twin control approach of twin data. The twin pair analyses complement our individual-based analyses and allow a new contribution on the role of genetic and common environment effects on BMI and mortality.

The main finding of this study is the increasing mortality, particularly due to CHD, with increasing BMI in clinically healthy men. Among women without clinically overt co-morbidities, BMI was not associated with overall mortality or cause-specific mortality. Among men, persistent acquired overweight is a considerable risk factor for CHD mortality.

\section{Disclosure}

The authors declared no conflict of interests.

\section{References}

1 Calle EE, et al: Body-mass index and mortality in a prospective cohort of U.S. adults. N Engl J Med 1999;341(15):1097-105.

2 Droyvold WB, et al: Weight change and mortality: the Nord-Trondelag Health Study. J Intern Med 2005; 257(4):338-45.

3 Jain A: Treating obesity in individuals and populations. BMJ 2005;331(7529):1387-90.

4 Manson JE, et al: Body weight and mortality among women. N Engl J Med 1995;333(11):677-85.

5 Pischon T, et al: General and abdominal adiposity and risk of death in Europe. N Engl J Med 2008; 359(20):2105-20.

6 WHO: Obesity: preventing and managing the global epidemic. World Health Organ Tech Rep Ser 2000; 894:i-xii, 1-253.

7 Whitlock G, et al: Body-mass index and causespecific mortality in 900000 adults: collaborative analyses of 57 prospective studies. Lancet 2009;373 (9669):1083-96.

8 Adams SA, et al: Physical activity levels among overweight and obese adults in South Carolina. South Med J 2003;96(6):539-43.

9 Jee SH, et al: Body-mass index and mortality in Korean men and women. N Engl J Med 2006;355(8): 779-87.

10 Flegal KM, Graubard BI, Williamson DF: Methods of calculating deaths attributable to obesity. Am J Epidemiol 2004,160(4):331-8
11 Romero-Corral A, et al: Association of bodyweight with total mortality and with cardiovascular events in coronary artery disease: a systematic review of cohort studies. Lancet 2006,368(9536):666-78.

12 Caban AJ, et al: Obesity in US workers: The National Health Interview Survey, 1986 to 2002. Am J Public Health 2005,95(9):1614-22.

13 IOTF. www.iotf.org.

14 National Cholesterol Education Program (NCEP) Expert Panel on Detection, Evaluation, and Treatment of High Blood Cholesterol in Adults (Adult Treatment Panel III): Third Report of the National Cholesterol Education Program (NCEP) Expert Panel on Detection, Evaluation, and Treatment of High Blood Cholesterol in Adults (Adult Treatment Panel III) final report. Circulation 2002; 106(25):3143-3421.

15 Pardo Silva MC, et al: Adult obesity and number of years lived with and without cardiovascular disease. Obesity (Silver Spring) 2006;14(7):1264-73.

16 Rosengren A, et al: Body mass index, other cardiovascular risk factors, and hospitalization for dementia. Arch Intern Med 2005;165(3):321-6.

17 Eilat-Adar S, et al: Intentional weight loss, blood lipids and coronary morbidity and mortality. Curr Opin Lipidol 2005;16(1):5-9.
18 French SA, et al: Prospective study of intentionality of weight loss and mortality in older women: the Iowa Women's Health Study. Am J Epidemiol 1999;149(6):504-14.

19 French SA, et al: Weight variability and incident disease in older women: the Iowa Women's Health Study. Int J Obes Relat Metab Disord 1997; 21(3):217-23.

20 Galanis DJ, et al: Relative weight, weight change, and risk of coronary heart disease in the Honolulu Heart Program. Am J Epidemiol 1998;147(4):37986.

21 Lee IM, Paffenbarger RS Jr: Change in body weight and longevity. JAMA 1992;268(15):2045-9.

22 Mikkelsen KL, et al: Independent effects of stable and changing body weight on total mortality. Epidemiology 1999;10(6):671-8.

23 Yaari S, Goldbourt U: Voluntary and involuntary weight loss: associations with long term mortality in 9,228 middle-aged and elderly men. Am J Epidemiol 1998;148(6):546-55.

24 Calle EE, Teras LR, Thun MJ: Obesity and mortality. N Engl J Med 2005;353(20):2197-9.

25 Diaz VA, Mainous AG 3rd, Everett CJ: The association between weight fluctuation and mortality: results from a population-based cohort study. J Community Health 2005;30(3):153-65. 
26 Folsom AR, et al: Weight variability and mortality: the Iowa Women's Health Study. Int J Obes Relat Metab Disord 1996;20(8):704-9.

27 Wannamethee SG, Shaper AG, Walker M: Weight change, weight fluctuation, and mortality. Arch Intern Med 2002;162(22):2575-80.

28 Sorensen TI, et al: Intention to lose weight, weight changes, and 18-y mortality in overweight individuals without co-morbidities. PLoS Med 2005:2(6): e171.

29 Kaprio J, Koskenvuo M: Twins, smoking and mortality: a 12-year prospective study of smoking-discordant twin pairs. Soc Sci Med 1989;29(9):1083-9.

30 Carmelli D, et al: Genetic influence on smoking - a study of male twins. N Engl J Med 1992;327(12): 829-33.

31 Kaprio J, Pulkkinen L, Rose RJ: Genetic and environmental factors in health-related behaviors: studies on Finnish twins and twin families. Twin Res 2002;5(5):366-71.

32 Kujala UM, Kaprio J, Koskenvuo M: Modifiable risk factors as predictors of all-cause mortality: the roles of genetics and childhood environment. Am J Epidemiol 2002;156(11):985-93.

33 Eisen SA, et al: The impact of cigarette and alcoho consumption on weight and obesity. An analysis of 1911 monozygotic male twin pairs. Arch Intern Med 1993;153(21):2457-63.

34 Pedersen NL, et al: Swedish early separated twins: identification and characterization. Acta Genet Med Gemellol (Roma) 1984;33(2):243-50.

35 Swan GE, Carmelli D, Cardon LR: The consumption of tobacco, alcohol, and coffee in Caucasian male twins: a multivariate genetic analysis. J Subst Abuse 1996;8(1):19-31.

36 Swan GE, et al: Smoking and alcohol consumption in adult male twins: genetic heritability and shared environmental influences. J Subst Abuse 1990;2(1): 39-50.

37 Kaprio J, Koskenvuo M: Genetic and environmental factors in complex diseases: the older Finnish Twin Cohort. Twin Res 2002;5(5):358-65.
38 French SA, et al: Weight variability in a population-based sample of older women: reliability and intercorrelation of measures. Int $\mathbf{J}$ Obes Relat Metab Disord 1995;19(1):22-9.

39 Jalkanen L, Tuomiletho J, Nissinen A, Puska P: Changes in body mass index in a Finnish population between 1972 and 1981. J Intern Med 1989;226: 163-70.

40 Korkeila M, et al: Predictors of major weight gain in adult Finns: stress, life satisfaction and personality traits. Int J Obes Relat Metab Disord 1998; 22(10):949-57.

41 Statistics Finland 2009 (cited July 11, 2009). Available from www.stat.fi/index_en.html.

42 Clement K, Sorensen TIA (eds): Obesity: Genomics and Postgenomics. London, Informa Healthcare, 2008, pp 29-48.

43 Korkeila M, et al: Consistency and change of body mass index and weight. A study on 5967 adult Finnish twin pairs. Int J Obes Relat Metab Disord 1995;19(5):310-7.

44 Korkeila M, et al: Weight-loss attempts and risk of major weight gain: a prospective study in Finnish adults. Am J Clin Nutr 1999;70(6):965-75.

45 Williams RL: A note on robust variance estimation for cluster-correlated data. Biometrics 2000; 56(2):645-6.

46 Swan GE, Carmelli D: Characteristics associated with excessive weight gain after smoking cessation in men. Am J Public Health 1995;85(1):73-7.

47 Hernan MA, Taubman SL: Does obesity shorten life? The importance of well-defined interventions to answer causal questions. Int J Obes (Lond) 2008;32(suppl 3):S8-14.

48 Flanders WD, Augestad LB: Adjusting for reverse causality in the relationship between obesity and mortality. Int J Obes (Lond) 2008;32(suppl 3:S42-6.

49 Flegal KM, et al: Excess deaths associated with underweight, overweight, and obesity. JAMA 2005; 293(15):1861-7.

50 Gregg EW, et al: Secular trends in cardiovascular disease risk factors according to body mass index in US adults. JAMA 2005;293(15):1868-74.
51 Cooper RS: Which factors confound or modify the relationship between body weight and mortality? Int J Obes (Lond) 2008;32(suppl 3):S47-51.

52 Durazo-Arvizu RA, Cooper RS: Issues related to modeling the body mass index-mortality association: the shape of the association and the effects of smoking status. Int J Obes (Lond) 2008;32(suppl 3): S52-5.

53 Rothman KJ: BMI-related errors in the measurement of obesity. Int J Obes (Lond) 2008;32(suppl 3): S56-9.

54 Reis JP, et al: Overall obesity and abdominal adiposity as predictors of mortality in u.s. White and black adults. Ann Epidemiol 2009;19(2):134-42.

55 Cesari M, et al: Skeletal muscle and mortality results from the InCHIANTI Study. J Gerontol A Biol Sci Med Sci 2009;64(3):377-84.

56 Gronniger JT: A semiparametric analysis of the relationship of body mass index to mortality. Am J Public Health 2006;96(1):173-8.

57 Cundiff DK: BMI: a poor surrogate for diet and exercise in assessing risk of death Int J Obes (Lond) 2006;30(8):1173-75.

58 Katzmarzyk PT, et al: The importance of waist circumference in the definition of metabolic syndrome: prospective analyses of mortality in men. Diabetes Care 2006;29(2):404-9.

59 Pietilainen $\mathrm{KH}$, et al: Global transcript profiles of fat in monozygotic twins discordant for BMI: pathways behind acquired obesity. PLoS Med 2008;5(3): e51.

60 Bigaard J, et al: Body fat and fat-free mass and allcause mortality. Obes Res 2004;12(7):1042-9.

61 Bigaard J, et al: Waist circumference and body composition in relation to all-cause mortality in middle-aged men and women. Int J Obes (Lond) 2005; 29(7):778-84

62 Bigaard J, et al: Waist circumference, BMI, smoking, and mortality in middle-aged men and women. Obes Res 2003;11(7):895-903. 